\title{
Estimation of standard penetration test value on cohesive soil using artificial neural network without data normalization
}

\author{
Soewignjo Agus Nugroho, Hendra Fernando, Reni Suryanita \\ Department of Civil Engineering, Riau University, Pekanbaru, Riau
}

\section{Article Info}

Article history:

Received Jun 2, 2021

Revised Dec 28, 2021

Accepted Jan 6, 2022

Keywords:

Artificial neural network

Cohesive soil

Cone penetration test

Data normalization

Standard penetration test

ABSTRACT

Artificial neural networks (ANNs) are often used recently by researchers to solve complex and nonlinear problems. Standard penetration test (SPT) and cone penetration test (CPT) are field tests that are often used to obtain soil parameters. There have been many previous studies that examined the value obtained through the SPT test with the CPT test, but the research carried out still uses equations that are linear. This research will conduct an estimated value of SPT on cohesive soil using CPT data in the form of end resistance and blanket resistance, and laboratory test data such as effective overburden pressure, liquid limit, plastic limit and percentage of sand, silt and clay. This study used 242 data with testing areas in several cities on the island of Sumatra, Indonesia. The developed artificial neural network will be created without data normalization. The final results of this study are in the form of root mean square error (RMSE) values 3.441, mean absolute error (MAE) 2.318 and $\mathrm{R}^{2} 0.9451$ for training data and RMSE 2.785, MAE 2.085, $\mathrm{R}^{2}$ 0.9792 for test data. The RMSE, MAE and $\mathrm{R}^{2}$ values in this study indicate that the ANN that has been developed is considered quite good and efficient in estimating the SPT value.
\end{abstract}

This is an open access article under the $\underline{C C B Y-S A}$ license.

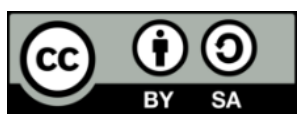

\section{Corresponding Author:}

Soewignjo Agus Nugroho

Department of Civil Engineering, Engineering Faculty, Riau University

Kampus Bina Widya, HR. Soebrantas Street KM 12.5, Pekanbaru, Riau, Indonesia

Email: nugroho.sa@eng.unri.ac.id

\section{INTRODUCTION}

Soil investigation is the first step that must be taken when building a construction. The soil investigation method depends on the soil condition and the function of the building. The standard penetration test (SPT) and the cone penetration test (CPT) are frequently used test methods at field sites. Usually investigations with soil investigations in the laboratory to obtain further parameters of the mechanical and physical properties of the soil. The SPT and CPT tests have their respective advantages and disadvantages. In the CPT test, only soil pressure data were obtained in the form of qc and fs values but no visual soil was obtained and the maximum depth of the test was $20 \mathrm{~m}$. While the SPT data obtained soil samples and the depth of the test can be tens of meters, but the test data obtained is only soil hardness (number of blows for penetration of $30 \mathrm{~cm}$ ). Therefore, this study was conducted to obtain the concept of a formula approach to be able to see the correlation of the SPT value from CPT data so that it can predict the soil strength (shear strength) at a depth of more than $20 \mathrm{~m}$.

In recent years, artificial neural networks have attracted a lot of research interest in solving a problem that is complex and has a nonlinear nature. An artificial neural network (ANN) is an information processing system that has characteristics similar to a biological neural network [1]. Therefore, this study will estimate the value of SPT using artificial neural network capabilities. The artificial neural network 
architecture consists of an input layer, an output layer and a hidden layer. Commonly used activation functions are binary sigmoid, bipolar sigmoid and linear functions. The learning algorithm that is most often used and effective in solving complex problems is the backpropagation algorithm. To find the best performing network, trial and error is carried out on the network architecture, activation functions and training parameters. The best artificial neural network model is obtained based on the smaller the error rate and the correlation coefficient value is close to 1 . Until the time this paper was published, ANN still received extensive attention by researchers and continues to be developed. In the geotechnical field, there have been many studies using the capabilities of this ANN. Related researches such as soil composition [2], soil classification [3], soil compaction [4], bearing capacity [5], unit weight [6], shallow foundation bearing capacity [7]-[9], estimated settlement in shallow foundations [10]-[12], preconsolidation stress [13], electrical resistivity of soil [14], deformation of geogrid-reinforced soil structures [15], tunnel boring machine performance [16], estimating cohesion of limestone samples [17] and many other related studies.

In estimating the value of SPT, artificial neural networks have also been widely used by previous researchers such as predicting the value of N-SPT using the general regression neural network [18] method at a location in Izmir, Turkey. In this study using input data in the form of the percentage of gravel, sand, silt and clay. From the research, it was found that the value of $\mathrm{R}^{2}$ was 0.9738 , root mean square error (RMSE) 0.04, mean absolute error (MAE) 0.01 in the training data, while the test data obtained the values of $R^{2}$ 0.9348, RMSE 0.08 and MAE 0.05. Another similar study is predicting N-SPT values based on CPT data at study locations in Dubai and Abu Dhabi, United Arab Emirates [19]. In this study, using input data in the form of end resistance value (qc), blanket resistance (fs) and soil effective pressure. From this study, the results obtained in the form of $\mathrm{R}$ value 0.95 and MAE 2.88 .

The research conducted by [18], [19] had several shortcomings that could be complemented by other researchers. In research [19], estimating the value of SPT is only based on the percentage of gravel, sand, silt and clay, while in research [18] only estimates the value of SPT based on the values of qc, fs and overburden effective pressure. In fact, the value of soil density is influenced by many variables both from the mechanical and physical properties of the soil. Due to the large number of variables that affect soil density, conventional correlation is considered less effective in estimating SPT values. This problem is what prompted the author to conduct research to estimate the value of SPT using the ability of ANNs by combining the thoughts of previous researchers, namely using input variables in the form of tip resistance (qc), sleeve resistance (fs) obtained from CPT and laboratory data in the form of effective overburden pressure, liquid limit, plastic limit, percentage of sand, silt and clay on the cohesive soil.

In general, the data used in artificial neural networks will normalize the data or transform the data into a range of values according to the activation function used. For example, if you use the binary sigmoid activation function, then the data must be normalized by transforming the data into a range of 0 to 1 or if use the bipolar sigmoid activation function, the data will be normalized by transforming the data into the range -1 to 1 . This method sometimes experiences difficulties because at times perform normalization, the data is not normalized to normal. Therefore, this research will carry out the process of developing an artificial neural network without normalizing the data. This research is expected to develop an artificial neural network without normalizing data with a low error rate, thus facilitating further research.

\section{RESEARCH METHOD}

\subsection{Research model}

In this study, the method used is to conduct direct research in the field and then process the research results using ANN software. Field tests carried out are SPT and CPT. The UDS sample obtained from the SPT test was carried out in the laboratory to obtain data on soil properties, both physical and mechanical properties of the soil. All data that has been obtained is then processed in Microsoft Excel software first for grouping data based on training data and test data. After grouping the data, the next step is to develop an artificial neural network using the ANN application. The research was conducted to obtain ANN with a smaller error value. In general, the research methodology can be seen in Figure 1.

\subsection{Data collection}

Data collection is an activity that aims to find the data needed in the research process in order to achieve the research objectives. In this study, the data needed is data on SPT, CPT and laboratory tests results. In SPT testing, the data required is the SPT value. In the CPT test, the data required is the value of end resistance (qc) and sleeve resistance (fs). In laboratory testing, the data required is the value of effective overburden pressure $\left(\sigma^{\prime} 0\right)$, the percentage of sand and fine grains. These data were obtained from the Laboratory of Soil and Rock mechanics, Civil Engineering department, University of Riau. The data obtained are the results of testing in several areas on the island of Sumatra, Indonesia, including the provinces of Riau, 
Riau Islands, Jambi, South Sumatra, West Sumatra and North Sumatra from 2005 to 2020. Statistics of all data can be seen in Table 1.

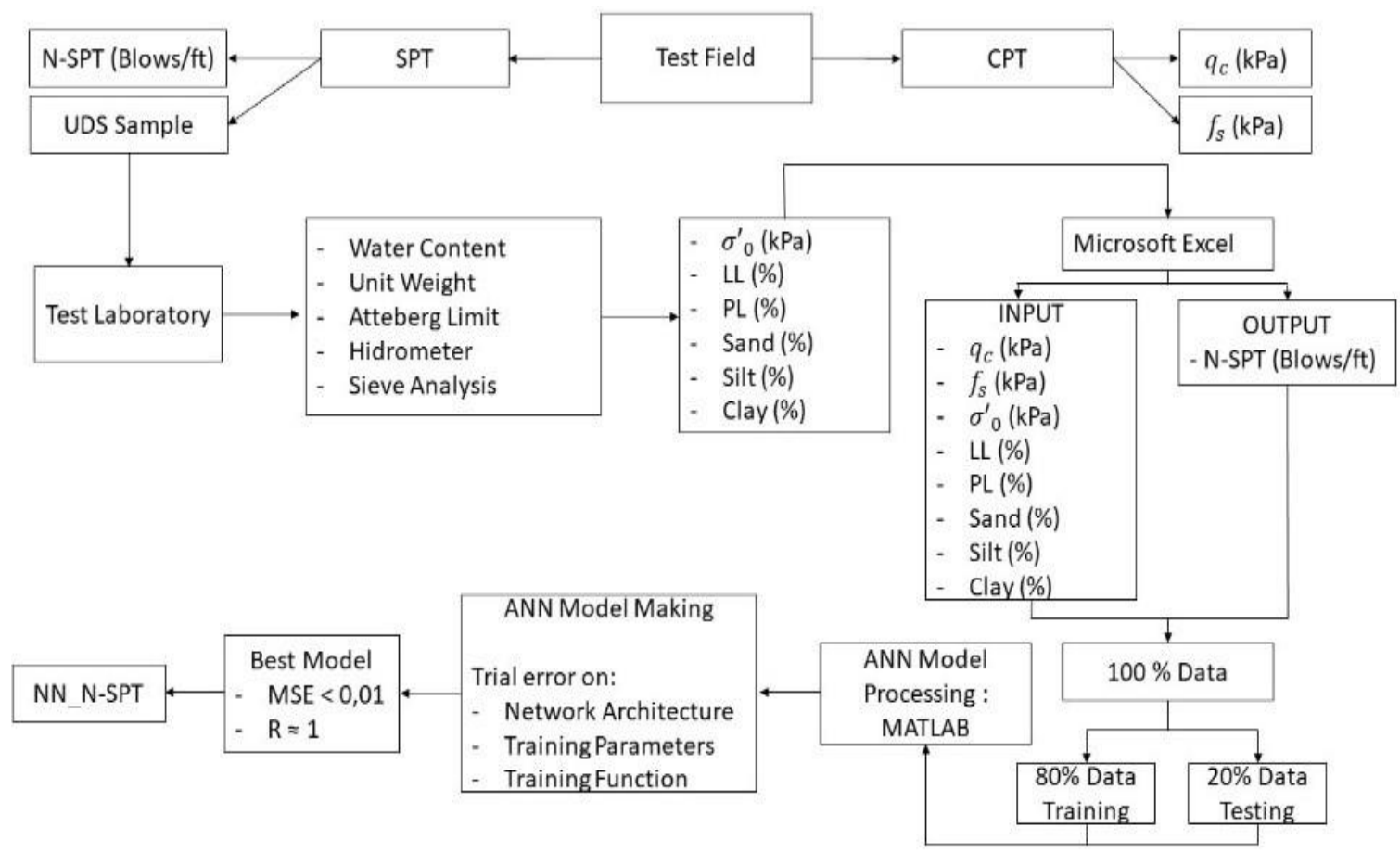

Figure 1. Research flow chart

Table 1. Collected data statistics

\begin{tabular}{cccccccccc}
\hline Variable & $\mathrm{q}_{\mathrm{c}}(\mathrm{kPa})$ & $\mathrm{f}_{\mathrm{s}}(\mathrm{kPa})$ & $\left(\sigma^{\prime}{ }_{0}\right)(\mathrm{kPa})$ & $\begin{array}{c}\text { Liquid } \\
\text { Limit }(\%)\end{array}$ & $\begin{array}{c}\text { Plastic } \\
\text { Limit }(\%)\end{array}$ & $\begin{array}{c}\text { Sand } \\
(\%)\end{array}$ & $\begin{array}{c}\text { Silt } \\
(\%)\end{array}$ & $\begin{array}{c}\text { Clay } \\
(\%)\end{array}$ & $\begin{array}{c}\mathrm{N}-\mathrm{SPT} \\
(\mathrm{blows} / \mathrm{ft})\end{array}$ \\
\hline Max & 24525 & 426.106 & 422.105 & 87.210 & 51.700 & 71.440 & 96.050 & 95.630 & 60 \\
Min & 98.100 & 0.100 & 23.490 & 16.940 & 12.650 & 0.070 & 2.970 & 0.010 & 1 \\
Mean & 3028.281 & 83.289 & 157.609 & 48.976 & 27.271 & 11.920 & 36.512 & 51.399 & 11.612 \\
\hline
\end{tabular}

\subsection{Design of artificial neural network (ANN) model}

The process of making ANNs is done by dividing the data into training data and test data. As much as $80 \%$ of the data is used as training data and $20 \%$ of the data will be used as test data. Training data is the data used to train the network by entering input data and output data. While the test data is data used to test the performance of the network being developed.

The design of the neural network model to be developed is adjusted to the purpose and nature of the data used. To predict the value of SPT that requires a relatively large amount of data input, the most appropriate method used is to create a network with a multilayer and backpropagation algorithm and supervised learning methods. Multilayer network architecture is the most appropriate solution for network models with large amounts of data and relatively complex problems. Multilayer network architecture consists of 3 layers, that is:

a. Input layer, this layer consists of several neurons whose number is adjusted according to the input pattern or variable.

b. Output layer, this layer consists of neurons whose number is in accordance with the desired output pattern or variable.

c. Hidden layer, this layer is between the input layer and the output layer, one or more hidden layers is determined based on a trial process and the number of neurons in the hidden layer is also determined based on a trial process to find the best performing network.

To get the network with the best performance, several trial variations can be carried out, that is:

a. Variations in network architecture (number of hidden layers and number of neurons in hidden layers). 
b. Variations on training functions (trainlm, traincgb, traingd, traingdm, traingda, traingdx, trainrp, traincgf, traincgp, or other training functions that have been provided).

c. Variations in the activation function (bipolar sigmoid, binary sigmoid or linear function).

d. Variations in training parameters (number of epochs, learning rate, goals, and validation checks).

The training process can be stopped if you have found a network with the best performance, namely a network with a smaller error value and an $\mathrm{R}$ value that is closer to 1 .

\subsection{Testing the artificial neural network (ANN) model}

To measure the accuracy and performance of the neural networks developed in producing SPT values, this study uses the RMSE and MAE values and the $\mathrm{R}^{2}$ value. The best performance is indicated by the small RMSE and MAE values and the $\mathrm{R}^{2}$ value that is close to 1 . To calculate the RMSE and MAE values, the following equation is used:

$$
\begin{aligned}
& R M S E=\sqrt{\frac{1}{n} \sum_{i=1}^{n}\left(f_{i}-y_{i}\right)^{2}} \\
& M A E=\frac{1}{n} \sum_{i=1}^{n}\left|f_{i}-y_{i}\right|
\end{aligned}
$$

Where, RMSE is root mean square error, MAE is mean absolute error, $\mathrm{f}_{\mathrm{i}}$ is original value, $\mathrm{y}_{\mathrm{i}}$ is forecast result value, and $\mathrm{n}$ is amount of data.

\subsection{Comparison of $\mathrm{ANN}$ with conventional equations}

The best artificial neural network model that has been obtained is then compared with conventional equations by several previous studies in determining the SPT value. Several previous studies in determining the value of the SPT can be seen in Table 2. Where Kc is the ratio between qc and N-SPT or Kc=qc/NSPT (in MPa), N is the SPT value, D50 is the grain diameter that passes $50 \%$ filter while FC is the fines content.

Table 2. The value of Kc is based on several studies

\begin{tabular}{cll}
\hline Reference & $\mathrm{Kc}(\mathrm{MPa})$ & \\
\hline$[20]$ & 0.77 & Sand \\
& 0.70 & Silty Sand \\
& 0.58 & Sandy Silt \\
{$[21]$} & 0.438 & Sand (Canada, Japan, Norwagia, China and Italy): D50=0.35+-0.23 mm \\
{$[22]$} & 0.508 & Clean Sand dan sandy silt, FC=3\%-35\% \\
& 0.568 & Sweden Sand \\
& 0.367 & Clay, Silty Clay and Silt \\
{$[23]$} & 0.423 & Sandy Silt, silt-sand \\
& 0.529 & Clean Sand dan Clayey Sand \\
& 0.374 & Sandy Clay, Silty Sand, Silty Clayey Sand \\
{$[24]$} & 0.572 & Gravelly Sand, Coarse Sand and Sand-Gravel \\
{$[25]$} & 0.37 & Clay dan silty sand (Tanzania): D50=0.38 mm \\
& 0.43 & Victoria Sand \\
{$[26]$} & 0.427 & Silty Sand \\
& 0.337 & Sandy Silt \\
& 0.319 & Silty Clay \\
\hline
\end{tabular}

\section{RESULTS AND DISCUSSION}

\subsection{Results of the model making stage}

From the research process, it was found that the best performance artificial neural network in estimating SPT values was a network with 2 hidden layer network architecture, 16 neurons in $1^{\text {st }}$ hidden layer and 8 neurons in $2^{\text {nd }}$ hidden layer. The training function used was traincgb. Network architecture can be seen in the Figure 2. In Figure 3 you can see the accuracy value of the network performance. The value of $R$ training is $0.97053, \mathrm{R}$ validation is 0.99052 , $\mathrm{R}$ Test is 0.95974 and $\mathrm{R}$ All is 0.97216.

\subsection{Weights and bias}

Based on the best ANN model obtained, then the weight and bias values are also obtained. This value can be used as a multiplier of a network. Tables 3 to 7 are the weight and bias values of the developed network model. 


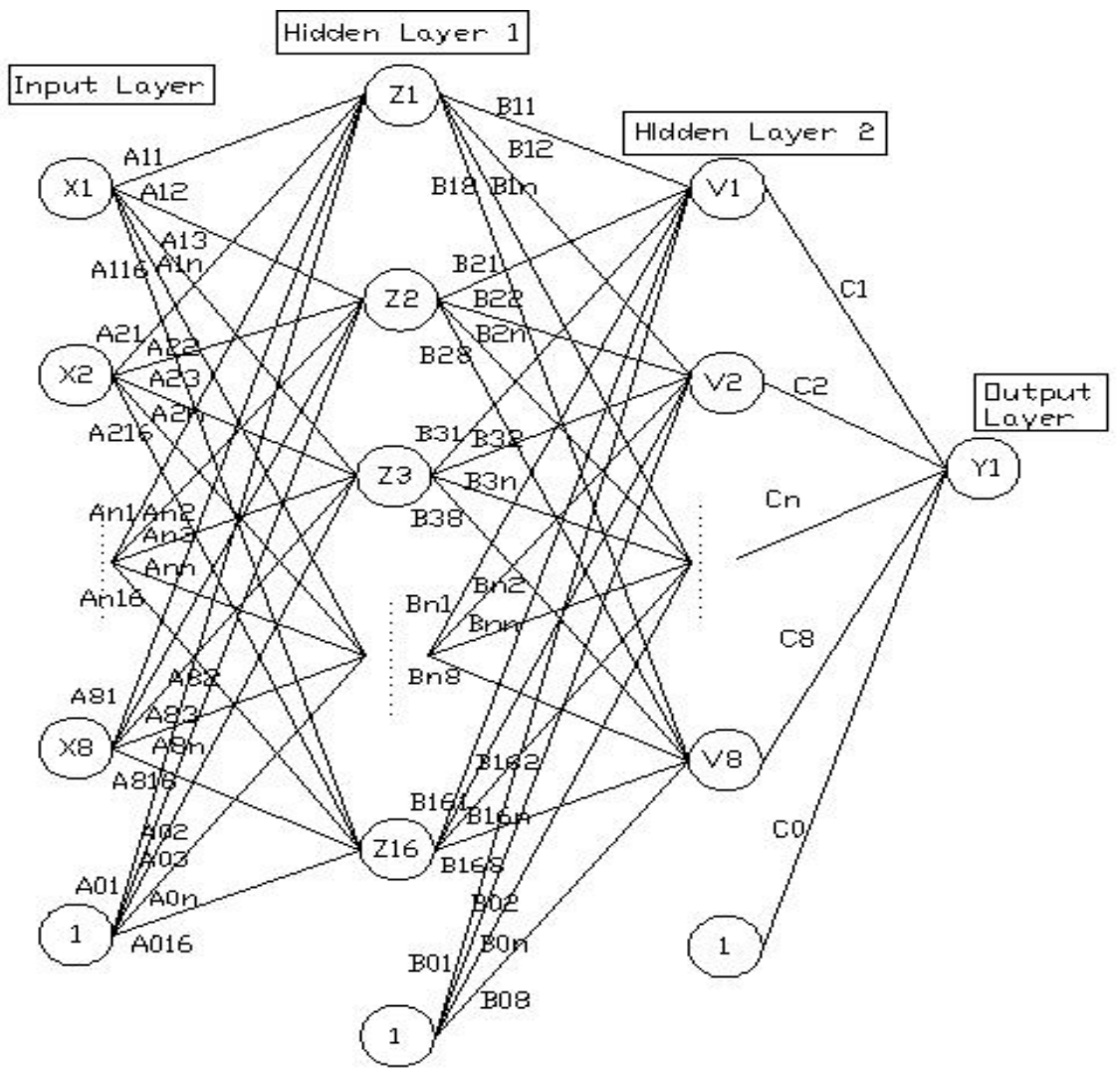

Figure 2. ANN architecture
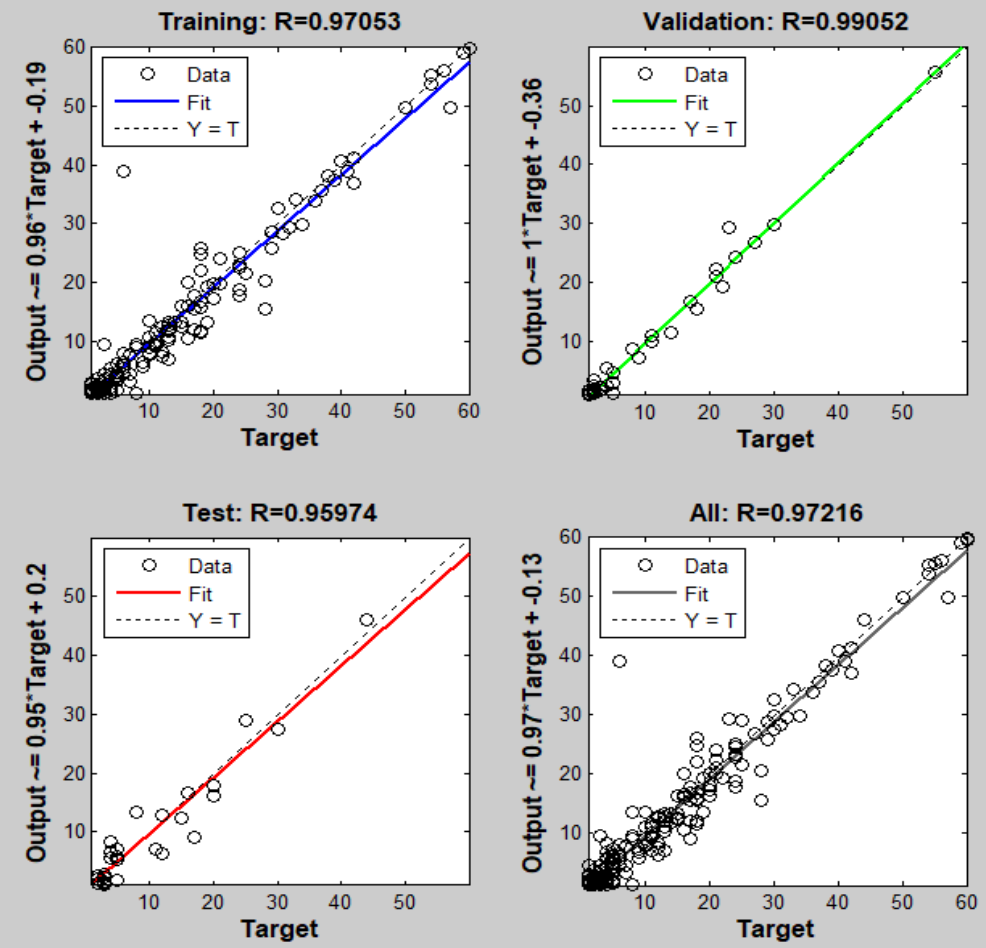

Figure. 3. ANN regression 
Table 3. Weights (A11-A816) from input layer to $1^{\text {st }}$ hidden layer, as shown in Figure 2

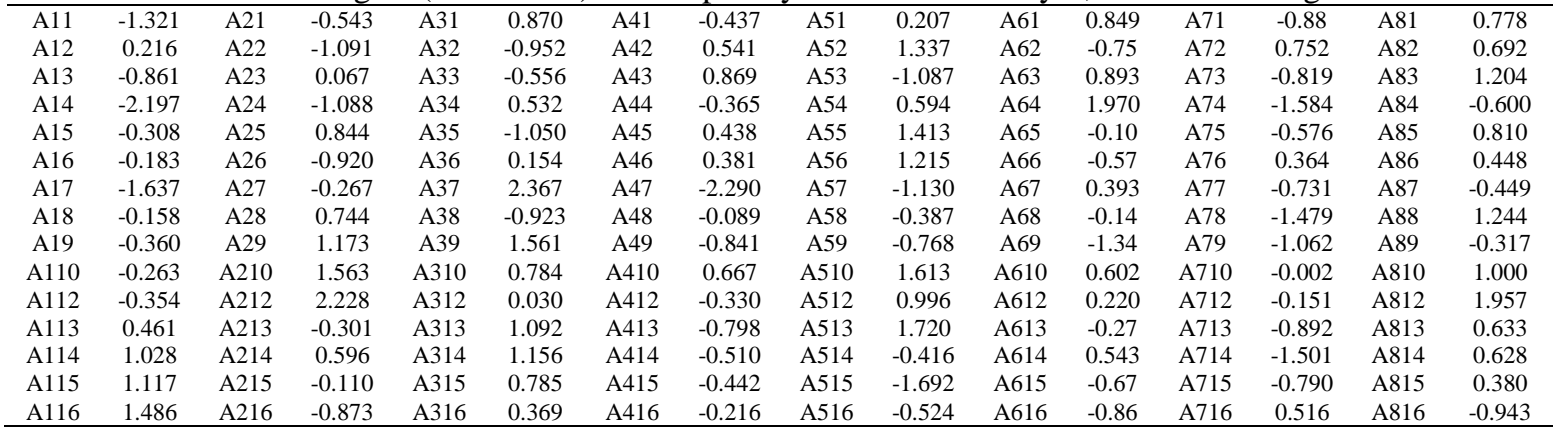

Table 4. Bias (A01-A016) from input layer to $1^{\text {st }}$ hidden layer, as shown in Figure 2

\begin{tabular}{cccccccc}
\hline $\mathrm{A} 001$ & $\mathrm{~A} 002$ & $\mathrm{~A} 003$ & $\mathrm{~A} 004$ & $\mathrm{~A} 005$ & $\mathrm{~A} 006$ & $\mathrm{~A} 007$ & $\mathrm{~A} 008$ \\
1.819 & -1.805 & 1.816 & 1.245 & 0.960 & -1.559 & 1.158 & -0.763 \\
$\mathrm{~A} 009$ & $\mathrm{~A} 010$ & $\mathrm{~A} 011$ & $\mathrm{~A} 012$ & $\mathrm{~A} 013$ & $\mathrm{~A} 014$ & $\mathrm{~A} 015$ & $\mathrm{~A} 016$ \\
0.109 & 0.111 & 0.185 & 0267 & -1.091 & 0.931 & 1.828 & 1.561 \\
\hline
\end{tabular}

Table 5. Weights (B11-B168) from $1^{\text {st }}$ hidden layer to $2^{\text {nd }}$ hidden layer, as shown in Figure 2

\begin{tabular}{|c|c|c|c|c|c|c|c|c|c|c|c|c|c|c|c|}
\hline B11 & -0.103 & B12 & -0.040 & $\bar{B} 13$ & -0.839 & B14 & 0.664 & B15 & -0.387 & B16 & -0.58 & B17 & -0.680 & B18 & -0.143 \\
\hline B41 & 0.380 & B42 & 0.230 & B43 & -0.835 & B44 & -0.079 & B45 & -0.277 & B46 & -1.19 & B47 & -0.542 & B48 & -2.204 \\
\hline B51 & 0.658 & B52 & -0.309 & B53 & -0.958 & B54 & -0.531 & B55 & 0.224 & B56 & 1.203 & B57 & 0.480 & B58 & 0.098 \\
\hline B71 & -0.290 & B72 & 1.169 & B73 & -0.555 & B74 & 0.120 & B75 & -0.083 & B76 & 0.465 & B77 & -0.227 & B78 & 0.508 \\
\hline B81 & -0.166 & B82 & 0.612 & B83 & 0.420 & B84 & -0.152 & B85 & 0.589 & B86 & 0.938 & B87 & -0.282 & B88 & 0.533 \\
\hline B91 & -0.183 & B92 & 0.763 & B93 & 0.763 & B94 & 0.792 & B95 & -0.407 & B96 & -0.41 & B97 & 0.439 & B98 & 1.688 \\
\hline B121 & -0.212 & B122 & -0.035 & B123 & -0.706 & B124 & 1.606 & B125 & 0.172 & B126 & -0.69 & B127 & -0.900 & B128 & 0.067 \\
\hline B131 & -0.549 & B132 & -0.208 & B133 & 0.378 & B134 & -0.593 & B135 & 1.056 & B136 & -0.06 & B137 & 0.697 & B138 & -0.171 \\
\hline B141 & -0.432 & B142 & -0.617 & B143 & 0.176 & B144 & -0.695 & B145 & 0.294 & B146 & 0.45 & B147 & -0.091 & B148 & 1.183 \\
\hline B151 & -0.031 & B152 & -0.641 & B153 & 0.143 & B154 & 0.011 & B155 & 0.544 & B156 & -0.48 & B157 & -0.030 & B158 & 0.966 \\
\hline B161 & -0.491 & B162 & -0.336 & B163 & -0.383 & B164 & -0.679 & B165 & 0.548 & B166 & -0.57 & B167 & -0.115 & B168 & 2.041 \\
\hline
\end{tabular}

Table 6. Bias (B01-A08) from $1^{\text {st }}$ hidden layer to $2^{\text {nd }}$ hidden layer, as shown in Figure 2

\begin{tabular}{cccccccc}
\hline B01 & B02 & B03 & B04 & B05 & B06 & B07 & B08 \\
\hline 1.789 & -1.458 & 0.769 & -0.520 & -0.257 & -0.664 & $-1,019$ & -1.286 \\
\hline
\end{tabular}

Table 7. Weights (C1-C8) and bas (C0) from $2^{\text {nd }}$ hidden layer to output layer, as shown in Figure 2

\begin{tabular}{ccccccccc}
\hline $\mathrm{C} 1$ & $\mathrm{C} 2$ & $\mathrm{C} 3$ & $\mathrm{C} 4$ & $\mathrm{C} 5$ & $\mathrm{C} 6$ & $\mathrm{C} 7$ & $\mathrm{C} 8$ & $\mathrm{C} 0$ \\
\hline-0.231 & -2.029 & -1.121 & -1.783 & 1.209 & -1.206 & 0.497 & 1.823 & 0.134 \\
\hline
\end{tabular}

\subsection{Results of the model testing stage}

The ANN that has been developed is then simulated to estimate the SPT value. This simulation is done using input data on training data and input data on test data. Furthermore, the SPT output value from the artificial neural network is compared with the original SPT value to obtain the RMSE and MAE values. RMSE and MAE values from the simulation results can be seen in Table 8 . To get the $\mathrm{R}^{2}$ value, the predicted SPT value data compared with the original SPT value is displayed in a linear regression graph. This linear regression graph can be seen in Figure 4. In Figure 4(a) is a linear regression line on the training data and in Figure $4(b)$ is a linear regression line on the test data.

Table 8. Measure of accuracy ANN

\begin{tabular}{ccc}
\hline Observation & Training data & Testing data \\
\hline RMSE & 3.278 & 2.012 \\
MAE & 1.783 & 1.328 \\
\hline
\end{tabular}


The next step to compare the effectiveness of using artificial neural networks in estimating SPT values, estimation using conventional correlation by [23], [24], [26] was also carried out. The use of this correlation results in the RMSE and MAE values in Table 9. The $\mathrm{R}^{2}$ value can be seen in the Figures 5(a) and (b) to Figures 7(a) and (b).

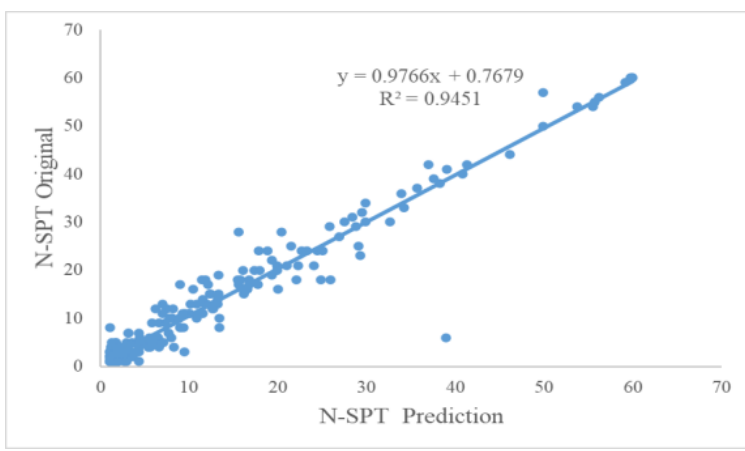

(a)

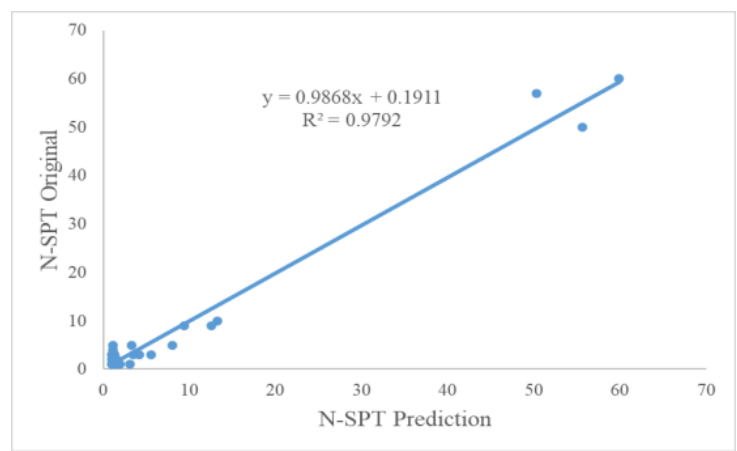

(b)

Figure 4. N-SPT prediction using ANNs (a) training data and (b) testing data

Table 9. Prediction of SPT value using conventional correlation

\begin{tabular}{ccccc}
\hline \multirow{2}{*}{ Research } & \multicolumn{2}{c}{ Training data } & \multicolumn{2}{c}{ Testing data } \\
\cline { 2 - 5 } & RMSE & MAE & RMSE & MAE \\
\hline$[23]$ & 9.005 & 5.001 & 7.964 & 2.936 \\
{$[24]$} & 8.787 & 4.928 & 7.833 & 3.001 \\
{$[26]$} & 8.327 & 4.908 & 7.658 & 3.259 \\
\hline
\end{tabular}

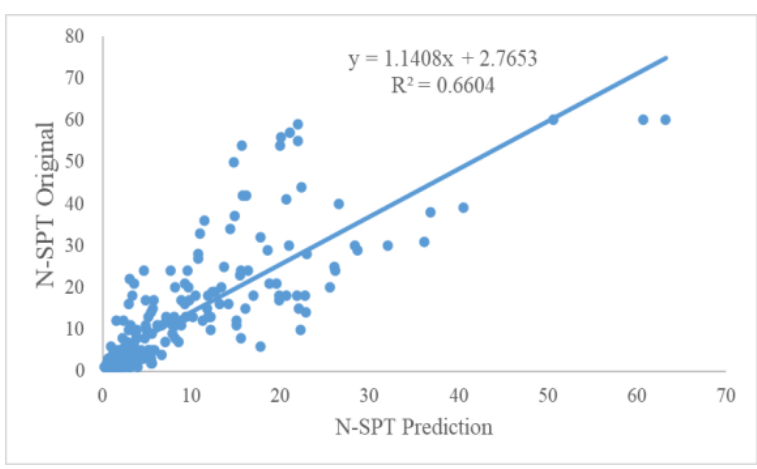

(a)

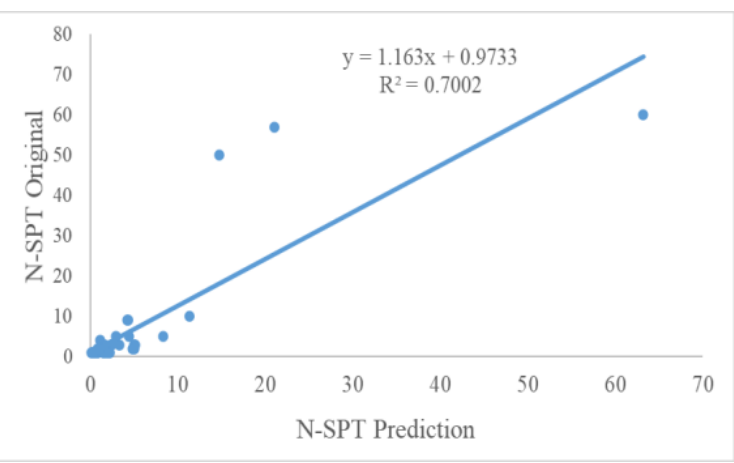

(b)

Figure 5. SPT value estimation using correlation by [23] (a) training data and (b) testing data

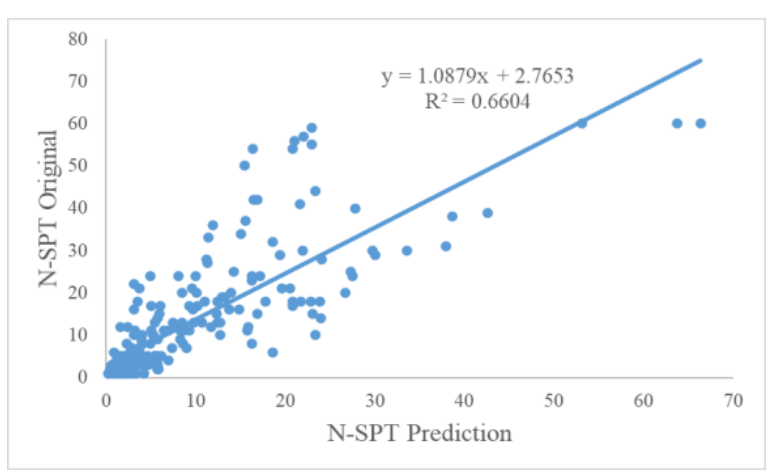

(a)

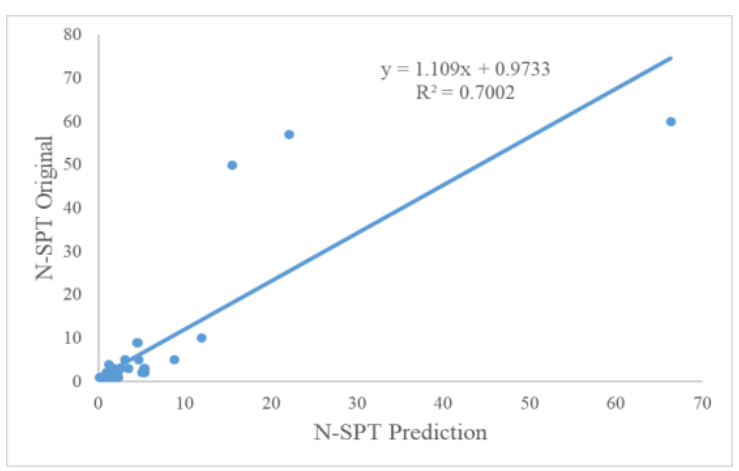

(b)

Figure 6. SPT value estimation using correlation by [24] (a) training data and (b) testing data 


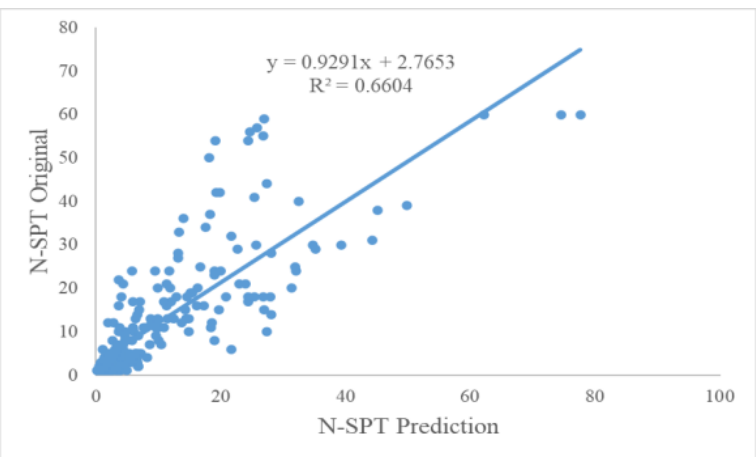

(a)

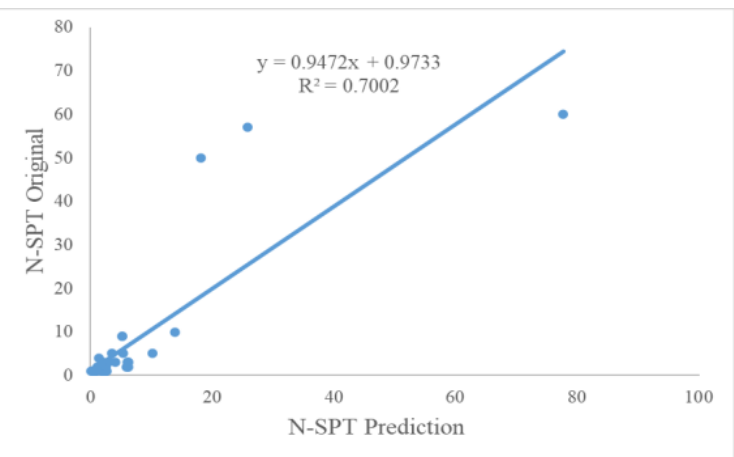

(b)

Figure 7. SPT value estimation using correlation by [26] (a) training data and (b) test data

\subsection{Design chart based on the best model}

Figures 8(a) and (b) are a design chart between the estimated SPT value and the original SPT value. On this graph, a linear regression line is drawn between the estimated SPT value and the original SPT value through calculations with artificial neural networks or calculations using conventional correlation by [23], [24], [26]. Based on this graph, it can be seen that the estimation results of SPT values using ANNs give better results than the other three conventional correlations. Estimating the value of SPT using ANN produces a correlation coefficient $\left(\mathrm{R}^{2}\right)$ that is closer to 1 (red linear regression line) compared to the other three correlations, that is the $\mathrm{R}^{2}$ value on the training data 0.9451 and on the 0.9792 test data.

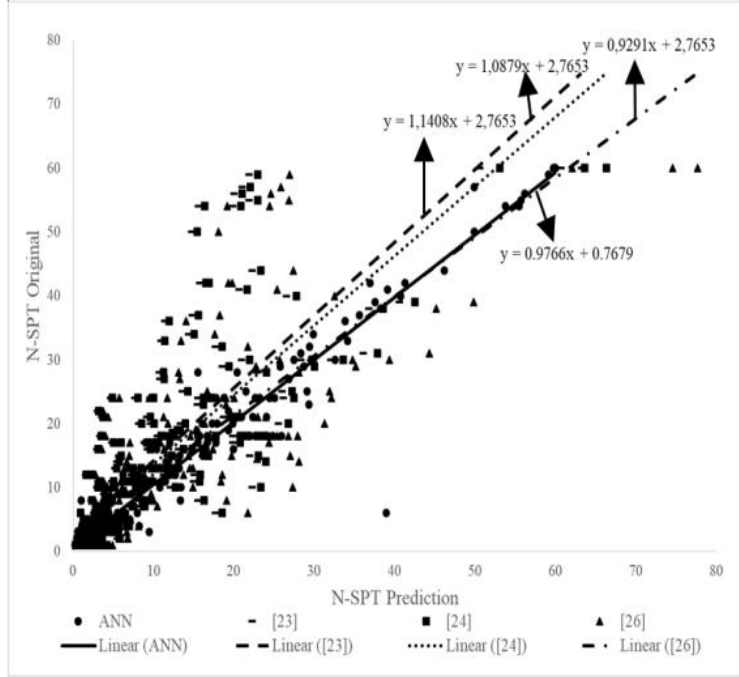

(a)

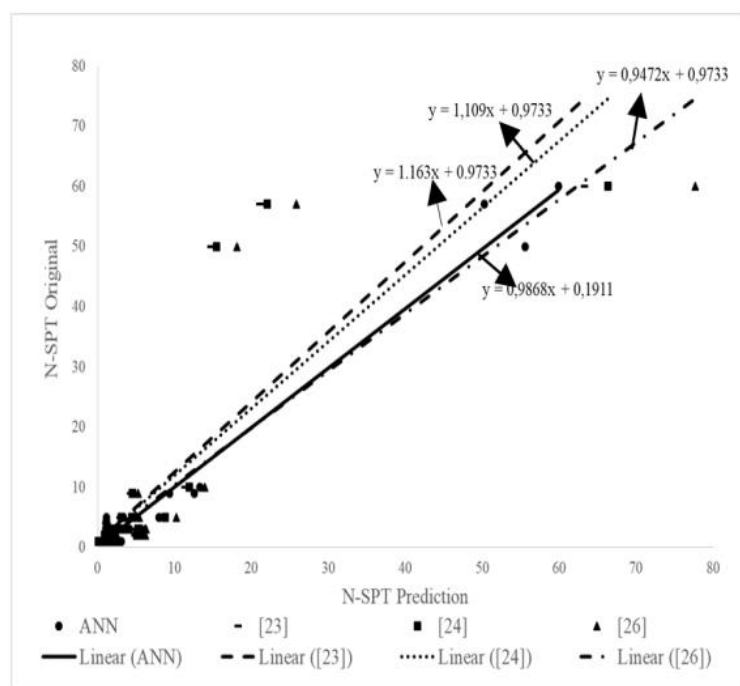

(b)

Figure 8. Design chart N-SPT predicition VS N-SPT original (a) training data (b) testing data

Figures 9(a) and (b) are design chart between tip resistance $\left(\mathrm{q}_{\mathrm{c}}\right)$ value and SPT value (N-SPT). In this graph, a combination of the relationship between qc and SPT values is displayed in the original data, the estimated data using an artificial neural network and the estimated data using conventional correlation by [23], [24], [26]. From this graph, it is clear that the linear regression line of the correlation between the $q_{c}$ value and the SPT value estimated by ANN almost coincides with the linear regression line of the relationship between the $\mathrm{q}_{\mathrm{c}}$ value and the SPT value in the original data. This means that the estimation results using ANN are almost close to the original value. Table 10 is a verification of the estimated data using an artificial neural network and using conventional correlation by [23], [24], [26]. It can be seen that the estimation results using an artificial neural network are almost close to the original value or have a small error value compared to using conventional correlation. 


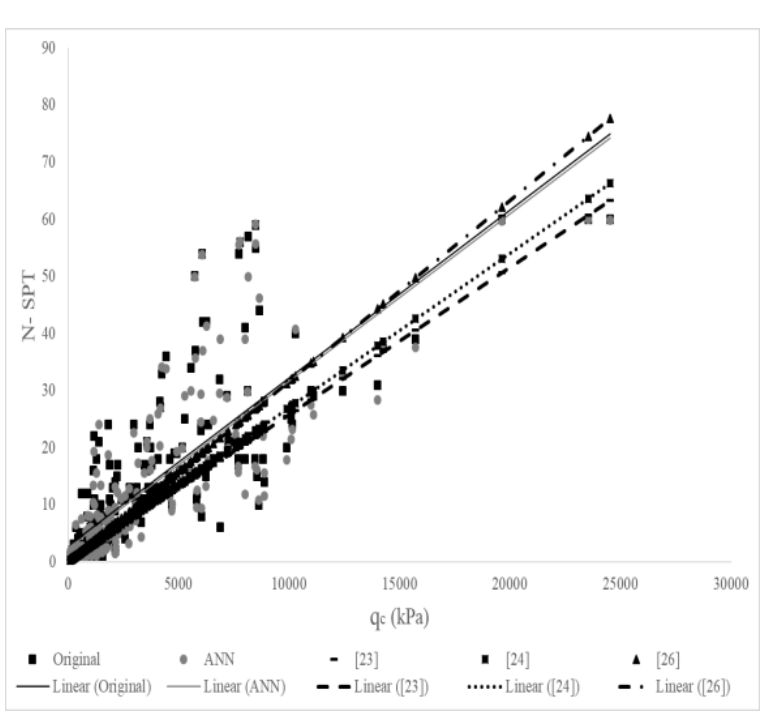

(a)

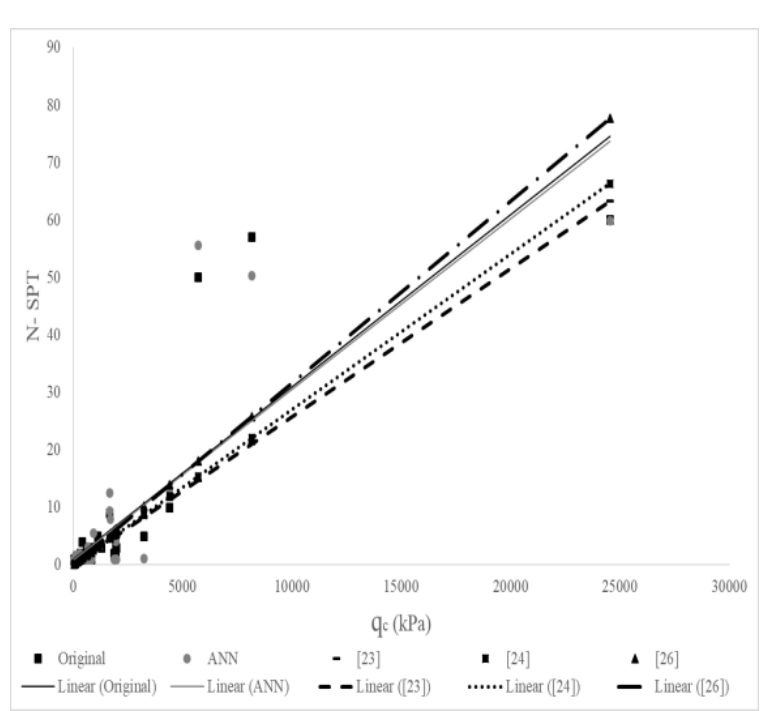

(b)

Figure 9. Design chart $\mathrm{q}_{\mathrm{c}}$ VS N-SPT (a) training data and (b) test data

Table 10. Verification of SPT value estimation data with ANN and conventional correlation

\begin{tabular}{|c|c|c|c|c|c|c|c|c|c|c|c|c|c|}
\hline \multirow[b]{2}{*}{$\begin{array}{l}\mathrm{N} \\
\mathrm{o}\end{array}$} & \multirow[b]{2}{*}{$\begin{array}{c}\mathrm{qc} \\
(\mathrm{KN} / \\
\mathrm{m} 2)\end{array}$} & \multirow[b]{2}{*}{$\begin{array}{c}\mathrm{fs} \\
(\mathrm{KN} / \mathrm{m} 2 \\
)\end{array}$} & \multirow[b]{2}{*}{$\begin{array}{c}\sigma^{\prime} 0 \\
(\mathrm{KN} / \\
\mathrm{m} 2)\end{array}$} & \multicolumn{2}{|c|}{ INPUT } & \multirow[b]{2}{*}{$\begin{array}{c}\text { Sand } \\
(\%)\end{array}$} & \multirow[b]{2}{*}{$\begin{array}{l}\text { Silt } \\
(\%)\end{array}$} & \multirow[b]{2}{*}{$\begin{array}{c}\text { Clay } \\
(\%)\end{array}$} & \multicolumn{5}{|c|}{ OUTPUT } \\
\hline & & & & $\begin{array}{l}\text { Liquid } \\
\text { Limit } \\
(\%)\end{array}$ & $\begin{array}{c}\text { Plastic } \\
\text { Limit } \\
(\%)\end{array}$ & & & & $\begin{array}{l}\text { Original } \\
\text { N-SPT } \\
\text { (blows/ } \\
\mathrm{ft} \text { ) }\end{array}$ & $\begin{array}{l}\text { ANN } \\
\text { N-SPT } \\
\text { (blows/ } \\
\text { ft) }\end{array}$ & $\begin{array}{c}{[23]} \\
\text { N-SPT } \\
\text { (blows/ } \\
\text { ft) }\end{array}$ & $\begin{array}{c}{[24]} \\
\text { N-SPT } \\
\text { (blows/ } \\
\text { ft) }\end{array}$ & $\begin{array}{c}{[26]} \\
\text { N-SPT } \\
\text { (blows/ } \\
\mathrm{ft} \text { ) }\end{array}$ \\
\hline 1 & $\begin{array}{c}837.6 \\
23\end{array}$ & 63.388 & $\begin{array}{c}199.1 \\
50\end{array}$ & 60.90 & 39.10 & 0.080 & 49.48 & 50.440 & 1 & 1.003 & 2.159 & 2.264 & 2.651 \\
\hline 2 & $\begin{array}{c}2256 . \\
300\end{array}$ & 135.939 & $\begin{array}{c}86.87 \\
0\end{array}$ & 42.520 & 22.510 & $\begin{array}{c}54.66 \\
0\end{array}$ & 8.540 & 36.800 & 5 & 4.867 & 5.815 & 6.098 & 7.140 \\
\hline 3 & $\begin{array}{c}8632 . \\
800\end{array}$ & 303.920 & $\begin{array}{c}302.1 \\
00\end{array}$ & 49.540 & 27.460 & 0.800 & 12.850 & 86.350 & 10 & 10.797 & 22.249 & 23.332 & 27.319 \\
\hline 4 & $\begin{array}{c}5477 . \\
250\end{array}$ & 179.850 & $\begin{array}{c}171.2 \\
50\end{array}$ & 58.500 & 27.600 & 0.560 & 28.480 & 70.960 & 16 & 16.497 & 14.117 & 14.803 & 17.333 \\
\hline 5 & $\begin{array}{c}5165 . \\
341\end{array}$ & 74.455 & $\begin{array}{c}252.9 \\
00\end{array}$ & 18.500 & 15.200 & $\begin{array}{c}53.14 \\
0\end{array}$ & 29.890 & 16.970 & 20 & 19.832 & 13.313 & 13.960 & 16.346 \\
\hline 6 & $\begin{array}{c}6005 . \\
121\end{array}$ & 153.456 & $\begin{array}{c}271.1 \\
85\end{array}$ & 71.270 & 32.570 & 2.020 & 18.260 & 79.720 & 24 & 24.404 & 15.477 & 16.230 & 19.004 \\
\hline 7 & $\begin{array}{c}8115 . \\
545\end{array}$ & 98.100 & $\begin{array}{c}319.7 \\
55\end{array}$ & 58.200 & 30.380 & 1.900 & 11.830 & 86.270 & 30 & 29.832 & 20.916 & 21.934 & 25.682 \\
\hline 8 & $\begin{array}{c}4227 . \\
218\end{array}$ & 420.046 & $\begin{array}{c}328.7 \\
55\end{array}$ & 49.140 & 29.020 & 3.420 & 46.320 & 50.260 & 33 & 34.153 & 10.895 & 11.425 & 13.377 \\
\hline 9 & $\begin{array}{c}10277 \\
.862\end{array}$ & 237.955 & $\begin{array}{c}131.1 \\
70\end{array}$ & 73.170 & 33.420 & 0.240 & 9.850 & 89.910 & 40 & 40.741 & 26.486 & 27.778 & 32.525 \\
\hline 10 & $\begin{array}{c}8647 . \\
892\end{array}$ & 426.106 & $\begin{array}{c}131.2 \\
15\end{array}$ & 75.070 & 30.350 & 3.360 & 8.860 & 87.780 & 44 & 46.131 & 22.288 & 23.373 & 27.367 \\
\hline 11 & $\begin{array}{c}5715 . \\
162\end{array}$ & 157.960 & $\begin{array}{c}185.4 \\
30\end{array}$ & 76.530 & 32.960 & 0.120 & 94.350 & 5.530 & 50 & 49.850 & 14.730 & 15.446 & 18.086 \\
\hline 12 & $\begin{array}{c}7776 . \\
446\end{array}$ & 183.372 & $\begin{array}{c}138.3 \\
05\end{array}$ & 61.890 & 34.400 & 2.180 & 90.380 & 7.440 & 56 & 56.127 & 20.042 & 21.017 & 24.609 \\
\hline 13 & $\begin{array}{c}23544 \\
.00\end{array}$ & 98.100 & $\begin{array}{c}176.5 \\
00\end{array}$ & 72.000 & 42.400 & 1.180 & 49.690 & 49.690 & 60 & 59.931 & 60.680 & 63.632 & 74.506 \\
\hline
\end{tabular}

\section{CONCLUSION}

ANN without data normalization is well developed in this study. The data used in this study were obtained from several locations on the island of Sumatra, Indonesia with a total of 244 data consisting of SPT, CPT and laboratory test data. This study uses input variables consisting of the value of tip resistance $\left(\mathrm{q}_{\mathrm{c}}\right)$, blanket resistance $\left(\mathrm{f}_{\mathrm{s}}\right)$, effective soil overburden pressure, liquid limit, plastic limit and percentage of sand, silt and clay. Meanwhile, the output variable is the SPT value. Based on the results of the research conducted, the network with the best performance is a network using network architecture with 2 hidden layers, 16 neurons in $1^{\text {st }}$ Hidden Layer and 8 neurons in $2^{\text {nd }}$ hidden layer, training function is traincgb, activation function is bipolar sigmoid and learning algorithm is backpropagation algorithm. This ANN model is said to be more effective in estimating the SPT value because it has a smaller error value than using conventional correlation. In the training data, the RMSE value for ANN was 3.278, MAE 1.783 and $\mathrm{R}^{2}$ 0.9451, while in the test data, the RMSE for ANN was 2.012, MAE 1.328, $\mathrm{R}^{2} 0.9792$. Therefore, based on 
this research, artificial neural networks without data normalization can be applied to other studies that have complex and nonlinear equations both in the geotechnical field and in other fields.

\section{ACKNOWLEDGEMENTS}

The authors would like to thank for the assistance and contribution from the Laboratory of Soil and Rock mechanics, Civil Engineering department, Universitas Riau and CV. Geotek Multi Services which has assisted the author in providing useful datas in this research, both field test data and laboratory test data. The data that has been provided is very useful in assisting the author in completing the objectives of this research.

\section{REFERENCES}

[1] H. Bolouri, "Book review: fundamentals of neural networks- architectures, algorithms, and applications: L. Fausett," The International Journal of Electrical Engineering and Education, vol. 32, no. 3, pp. 284-285, Jul. 1995, doi: 10.1177/002072099503200320.

[2] P. U. Kurup and E. P. Griffin, "Prediction of soil composition from CPT data using general regression neural network," Journal of Computing in Civil Engineering, vol. 20, no. 4, pp. 281-289, Jul. 2006, doi: 10.1061/(ASCE)0887-3801(2006)20:4(281).

[3] C. Reale, K. Gavin, L. Librić, and D. Jurić-Kaćunić, "Automatic classification of fine-grained soils using CPT measurements and artificial neural networks," Advanced Engineering Informatics, vol. 36, pp. 207-215, Apr. 2018, doi: 10.1016/j.aei.2018.04.003.

[4] J. Jayan and N. Sankar, "Prediction of compaction parameters of soils using artificial neural network," Asian Journal of Engineering and Technology, vol. 3, no. 4, 2015.

[5] T. Gnananandarao, V. N. Khatri, and R. K. Dutta, "Prediction of bearing capacity of H shaped skirted footings on sand using soft computing techniques," Archives of Materials Science and Engineering, vol. 2, no. 103, pp. 62-74, Jun. 2020, doi: 10.5604/01.3001.0014.3356.

[6] G. Straż and A. Borowiec, "Estimating the unit weight of local organic soils from laboratory tests using artificial neural networks," Applied Sciences, vol. 10, no. 7, Art. no. 2261, Mar. 2020, doi: 10.3390/app10072261.

[7] Y. L. Kuo, M. B. Jaksa, A. V. Lyamin, and W. S. Kaggwa, "ANN-based model for predicting the bearing capacity of strip footing on multi-layered cohesive soil," Computers and Geotechnics, vol. 36, no. 3, pp. 503-516, Apr. 2009, doi: 10.1016/j.compgeo.2008.07.002.

[8] D. Padmini, K. Ilamparuthi, and K. P. Sudheer, "Ultimate bearing capacity prediction of shallow foundations on cohesionless soils using neurofuzzy models," Computers and Geotechnics, vol. 35, no. 1, pp. 33-46, Jan. 2008, doi: 10.1016/j.compgeo.2007.03.001.

[9] P. Provenzano, S. Ferlisi, and A. Musso, "Interpretation of a model footing response through an adaptive neural fuzzy inference system," Computers and Geotechnics, vol. 31, no. 3, pp. 251-266, Apr. 2004, doi: 10.1016/j.compgeo.2004.03.001.

[10] M. A. Shahin, H. R. Maier, and M. B. Jaksa, "Settlement prediction of shallow foundations on granular soils using B-spline neurofuzzy models," Computers and Geotechnics, vol. 30, no. 8, pp. 637-647, Dec. 2003, doi: 10.1016/j.compgeo.2003.09.004.

[11] M. A. Shahin, M. B. Jaksa, and H. R. Maier, "Neural network based stochastic design charts for settlement prediction," Canadian Geotechnical Journal, vol. 42, no. 1, pp. 110-120, Feb. 2005, doi: 10.1139/t04-096.

[12] Y.-L. Chen, R. Azzam, and F.-B. Zhang, "The displacement computation and construction pre-control of a foundation pit in Shanghai utilizing FEM and intelligent methods," Geotechnical and Geological Engineering, vol. 24, no. 6, pp. 1781-1801, Dec. 2006, doi: 10.1007/s10706-006-6807-6.

[13] S. Çelik and Ö. Tan, "Determination of preconsolidation pressure with artificial neural network," Civil Engineering and Environmental Science, vol. 22, no. 4, pp. 217-231, Dec. 2005, doi: 10.1080/10286600500383923.

[14] B. Alsharari, A. Olenko, and H. Abuel-Naga, "Modeling of electrical resistivity of soil based on geotechnical properties," Expert Systems with Applications, vol. 141, Art. no. 112966, Mar. 2020, doi: 10.1016/j.eswa.2019.112966.

[15] E. Momeni, A. Yarivand, M. B. Dowlatshahi, and D. J. Armaghani, "An efficient optimal neural network based on gravitational search algorithm in predicting the deformation of geogrid-reinforced soil structures," Transportation Geotechnics, vol. 26, Art. no. 100446, Jan. 2021, doi: 10.1016/j.trgeo.2020.100446.

[16] M. Koopialipoor, A. Fahimifar, E. N. Ghaleini, M. Momenzadeh, and D. J. Armaghani, "Development of a new hybrid ANN for solving a geotechnical problem related to tunnel boring machine performance," Engineering with Computers, vol. 36, no. 1, pp. 345-357, Jan. 2020, doi: 10.1007/s00366-019-00701-8.

[17] M. Khandelwal et al., "Implementing an ANN model optimized by genetic algorithm for estimating cohesion of limestone samples," Engineering with Computers, vol. 34, no. 2, pp. 307-317, Apr. 2018, doi: 10.1007/s00366-017-0541-y.

[18] Y. Erzin and Y. Tuskan, "Prediction of standard penetration test (SPT) value in Izmir, Turkey using radial basis neural network," Celal Bayar Üniversitesi Fen Bilimleri Dergisi, Jun. 2017, doi: 10.18466/cbayarfbe.319912.

[19] B. Tarawneh, "Predicting standard penetration test N-value from cone penetration test data using artificial neural networks," Geoscience Frontiers, vol. 8, no. 1, pp. 199-204, Jan. 2017, doi: 10.1016/j.gsf.2016.02.003.

[20] N. Akca, "Correlation of SPT-CPT data from the United Arab Emirates," Engineering Geology, vol. 67, no. 3-4, pp. 219-231, Jan. 2003, doi: 10.1016/S0013-7952(02)00181-3.

[21] P. Mayne, "In-situ test calibrations for evaluating soil parameters," in Characterisation and Engineering Properties of Natural Soils, vol. 3-4, Taylor \&amp; Francis, 2006, pp. 1601-1652.

[22] S. M. Ahmed, S. W. Agaiby, and A. H. Abdel-Rahman, "A unified CPT-SPT correlation for non-crushable and crushable cohesionless soils," Ain Shams Engineering Journal, vol. 5, no. 1, pp. 63-73, Mar. 2014, doi: 10.1016/j.asej.2013.09.009.

[23] A. Shahri, C. Juhlin, and A. Malemir, "A reliable correlation of SPT-CPT data for southwest of Sweden.," electronic Journal Of Geotechnical Engineering, 2014.

[24] M. I. Lingwanda, S. Larsson, and D. L. Nyaoro, "Correlations of SPT, CPT and DPL data for sandy soil in Tanzania," Geotechnical and Geological Engineering, vol. 33, no. 5, pp. 1221-1233, Oct. 2015, doi: 10.1007/s10706-015-9897-1.

[25] M. D. dos Santos and K. V. Bicalho, "Proposals of SPT-CPT and DPL-CPT correlations for sandy soils in Brazil," Journal of Rock Mechanics and Geotechnical Engineering, vol. 9, no. 6, pp. 1152-1158, Dec. 2017, doi: 10.1016/j.jrmge.2017.08.001.

[26] M. Alam et al., "Empirical SPT-CPT correlation for soils from Lahore, Pakistan," IOP Conference Series: Materials Science and Engineering, vol. 414, no. 1, p. 012015, Sep. 2018, doi: 10.1088/1757-899X/414/1/012015. 


\section{BIOGRAPHIES OF AUTHORS}

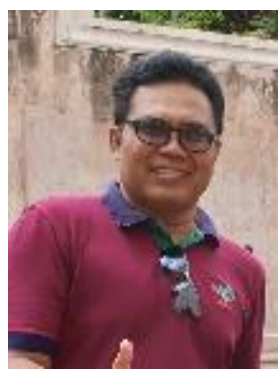

Soewignjo Agus Nugroho (D) 8 SC $\mathrm{P}$ is a Graduate from Gadjah Mada University Majoring in Geotechnical Engineering. Head of Soil Mechanics Laboratory Universitas Riau 2012 to 2014. Coordinator of geotechnical engineering research since 2010 at civil engineering department at same office. He is currently as senior researcher and associate professor with expert experience in soil investigation and machine learning. Recent decades research on slope stability, geo-disaster, soil stability, improvement and machine learning. He can be contacted at email: nugroho.sa@eng.unri.ac.id.

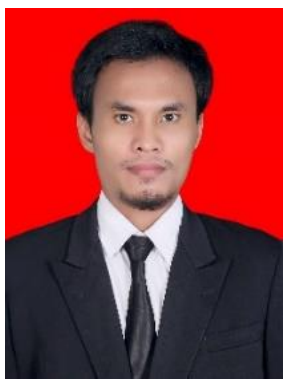

Hendra Fernando (D) 8. SC $\mathrm{P}$ is a graduate of civil engineering from the University of Riau, Indonesia. He is currently as a research and assistant professor in geotechnical engineering. He can be contacted at email: hendra.fernando6188@ student.inri.ac.id

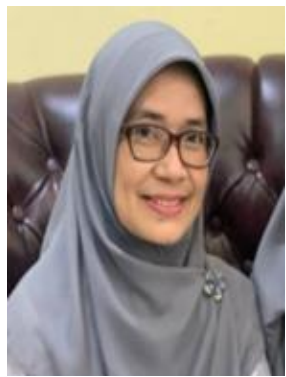

Reni Suryanita (D) 8d SC P is a currently as Associate Professor in Civil Engineering Department, Engineering Faculty, Universitas Riau, Pekanbaru, Indonesia. Her undergraduate education was completed in the Civil Engineering Department of Andalas University in 1996. Meanwhile, she got master's degree in 1998 in the Department of Civil Engineering, Bandung Institute of Technology. Completed Doctoral at Universiti Teknologi Malaysia in 2014. Her research interest includes artificial intelligent, bridge engineering, structure engineering and earthquake engineering. She can be contacted at email: reni.suryanita@eng.unri.ac.id. 